\title{
SARS-CoV-2 Infection in Pregnancy - a Review of the Current Literature and Possible Impact on Maternal and Neonatal Outcome
}

\author{
SARS-CoV-2-Infektion in der Schwangerschaft - \\ eine Übersichtsarbeit über die aktuelle Literatur und mögliche \\ Einflüsse auf das maternale und neonatale Outcome
}

\section{(우)(1) (요 $\Theta$}

Authors

Florian M. Stumpfe ${ }^{1}$, Adriana Titzmann ${ }^{1}$, Michael O. Schneider ${ }^{1}$, Patrick Stelzl ${ }^{1}$, Sven Kehl ${ }^{1}$, Peter A. Fasching ${ }^{1}$, Matthias W. Beckmann ${ }^{1}$, Armin Ensser ${ }^{2}$

\author{
Affiliations \\ 1 Universitätsklinikum Erlangen, Frauenklinik, Erlangen, \\ Germany \\ 2 Universitätsklinikum Erlangen, Virologisches Institut, \\ Erlangen, Germany
}

Key words

COVID-19, coronavirus, SARS-CoV-2, 2019-nCoV, pregnancy

Schlüsselwörter

COVID-19, Coronavirus, SARS-CoV-2, 2019-nCoV, Schwangerschaft

$\begin{array}{ll}\text { received } & 8.3 .2020 \\ \text { revised } & 9.3 .2020 \\ \text { accepted } & 10.3 .2020\end{array}$

\section{Bibliography}

DOI https://doi.org/10.1055/a-1134-5951

published online 26.03.2020 | Geburtsh Frauenheilk 2020; 80: 380-390 @ Georg Thieme Verlag KG Stuttgart .

New York | ISSN 0016-5751

\section{Correspondence}

Dr. med. Florian M. Stumpfe

Universitätsklinikum Erlangen - Frauenklinik

Universitätsstraße 21-23, 91054 Erlangen, Germany

florian.stumpfe@uk-erlangen.de

$\Theta$

Deutsche Version unter:

https://doi.org/10.1055/a-1134-5951

\section{ABSTRACT}

In December 2019, cases of pneumonia of unknown cause first started to appear in Wuhan in China; subsequently, a new coronavirus was soon identified as the cause of the illness, now known as Coronavirus Disease 2019 (COVID-19).
Since then, infections have been confirmed worldwide in numerous countries, with the number of cases steadily rising. The aim of the present review is to provide an overview of the new severe acute respiratory syndrome (SARS) coronavirus 2 (SARS-CoV-2) and, in particular, to deduce from it potential risks and complications for pregnant patients. For this purpose, the available literature on cases of infection in pregnancy during the SARS epidemic of 2002/2003, the MERS (Middle East respiratory syndrome) epidemic ongoing since 2012, as well as recent publications on cases infected with SARS-CoV-2 in pregnancy are reviewed and reported. Based on the literature available at the moment, it can be assumed that the clinical course of COVID-19 disease may be complicated by pregnancy which could be associated with a higher mortality rate. It may also be assumed at the moment that transmission from mother to child in utero is unlikely. Breastfeeding is possible once infection has been excluded or the disease declared cured.

\section{ZUSAMMENFASSUNG}

Im Dezember 2019 traten in Wuhan in China erstmals Fälle mit Pneumonien unbekannter Ursache auf; in der Folge konnte rasch ein neues Coronavirus als Ursache der inzwischen als Coronavirus Disease 2019 (COVID-19) bezeichneten Erkrankung identifiziert werden. Seither sind Infektionen in vielen Ländern weltweit bestätigt worden, und die Fallzahl steigt stetig. Diese Übersichtsarbeit soll einen Überblick über das neue Severe Acute Respiratory Syndrome (SARS) Coronavirus 2 (SARS-CoV-2) geben und insbesondere mögliche Risiken und Komplikationen für schwangere Patientinnen ableiten. Hierfür wurde die verfügbare Literatur zu Infektionsfällen in der Schwangerschaft während der SARS-Epidemie 2002/2003, der seit 2012 laufenden MERS-(Middle-East-respiratory-syndrome-)Epidemie, sowie aktuelle Publikationen zu Infektionsfällen mit SARS-CoV-2 während der Schwangerschaft gesichtet und beschrieben. Zum aktuellen Zeitpunkt ist aufgrund dieser verfügbaren Literatur davon auszugehen, dass der Ver- 
lauf einer COVID-19-Erkrankung durch eine Schwangerschaft verkompliziert werden kann und diese mit einer höheren Mortalität assoziiert sei könnte. Es ist zudem aktuell davon aus- zugehen, dass eine Transmission von der Mutter auf das Kind in utero unwahrscheinlich ist. Stillen ist nach Ausschluss einer Infektion oder abgeheilter Erkrankung möglich.

\section{Introduction}

The number of cases infected with the new coronavirus (SARSCoV-2) is currently rising daily. So far, 23129 cases have been confirmed in Germany (last updated 22.03.2020 12:43 hrs). The number of cases worldwide is over 300000 - and still rising.

Coronaviruses (CoV) are RNA viruses and belong to the order of nidoviruses. Until December 2019, the family of coronaviruses comprised six human pathogenic species, amongst these the severe acute respiratory syndrome coronavirus (SARS-CoV) and the Middle East respiratory syndrome coronavirus (MERS-CoV). With SARS-CoV-2, a seventh human pathogenic species has been added [1,2]. Four "endemic" species (HKU1, OC43, 229E, NL63) have so far been of clinical significance, often producing rather mild symptoms of a cold, and are responsible for about $10 \%$ of seasonal airway diseases not caused by influenza. SARS-CoV and MERS-CoV, which cause very serious airway symptoms and diseases associated with a high mortality rate (10-30\%), have so far been limited to a one-off outbreak in 2002/2003 (SARS-CoV) or were predominantly of regional significance.

Since the occurrence of cases is only recent, there is so far little evidence available on the clinical course of a SARS-CoV-2 infection outside China. In particular, little is known about the clinical course and possible risks and complications for infected pregnant patients and newborn children of infected mothers. The aim of this article, therefore, is to provide an overview of disease courses involving infections with the highly pathogenic coronaviruses SARS-CoV and MERS-CoV and to deduce from this possible risks for pregnant women suffering from a SARS-CoV-2 infection. In addition, the publications to date on infections with SARS-CoV-2 in pregnancy will be presented.

\section{Overview/Review}

The first cases of a form of pneumonia of unknown cause were observed at the beginning of December 2019 in Wuhan, the capital of Hubei Province, in Central China [3].

The point of origin is currently assumed to be the Wuhan Huanan Seafood Wholesale Market [4], in the vicinity of which transmission of a zoonotic pathogen to humans occurred.

Between 31st December 2019 and 3rd January 2020, 44 cases were reported to the World Health Organisation (WHO) - since then confirmed cases of a SARS-CoV-2 infection have been steadily rising. By 22.03.2020 (last update 12:43 hrs), 311988 cases were known to have been confirmed worldwide [5].

At the end of December 2019, sputum samples were taken by bronchoalveolar lavage from three patients suffering from pneumonia of unknown cause, who had been to the market a few days before onset of their symptoms, and from this material the new virus SARS-CoV-2 was identified by high-throughput sequencing (next generation sequencing) and PCR [6] (• Fig. 1).
Beginning of December 2019

The first infected patient presents symptoms.

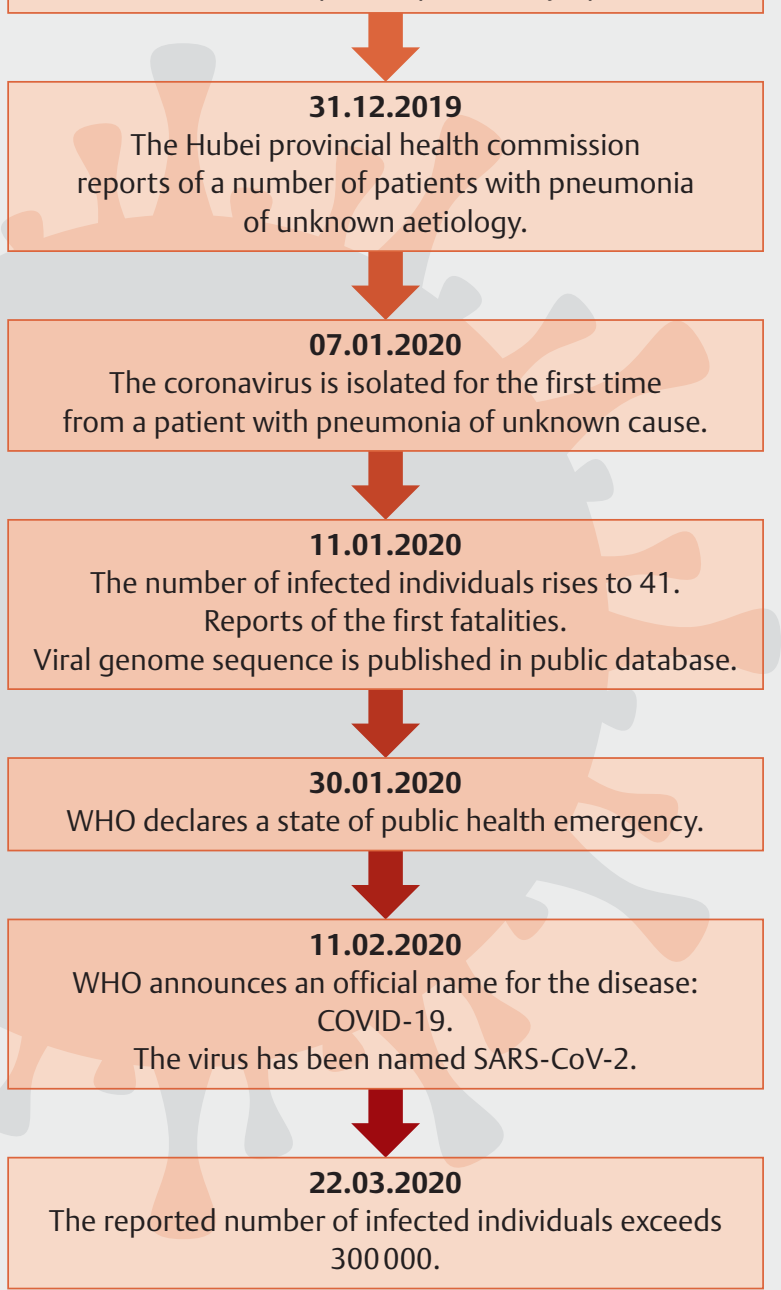

- Fig. 1 Important milestones of the infections with SARS-CoV-2 since December 2019.

Based on recent studies, men are more often and more severely affected than women; the median age of onset is 47 years $[7,8]$. The majority of observed deaths involves individuals over 70 years of age and those with severe underlying conditions. The disease is usually only mild in children and adolescents.

According to current knowledge, transmission of SARS-CoV-2 is via droplet infection [4]. Like SARS-CoV, SARS-CoV-2 is also regularly isolated from stool, where it is also infectious, although the epidemiologic relevance of a faecal-oral transmission is as yet unclear [9-11]. The incubation period is approx. 5.2 (95\% confidence interval: 4.1-7; 95th percentile: 12.5) days [3]. Current 
data published by the WHO, based on 55924 cases of laboratoryconfirmed SARS-CoV-2 infection, show that approx. $80 \%$ of cases have a mild to moderate clinical course and heal spontaneously. Asymptomatic cases occur at a still unknown rate. - Table 1 presents the typical symptoms. Not all cases of this group develop pneumonia.

In $13.8 \%$ of cases, disease progression is severe, associated with shortness of breath, a respiratory rate of $\geq 30$ per minute, blood oxygen saturation $\leq 93 \%, \mathrm{PaO}_{2} / \mathrm{FiO}_{2}$ ratio $<300$ and/or radiologically proven pulmonary infiltrates. In $6.1 \%$ of SARS-CoV-2 infections, a critical course is evident, associated with respiratory failure, septic shock and/or multiple organ failure [12].

Details about mortality rates are heterogeneous at this point in time. The WHO puts them at 3.8\% [12]. However, it should be noted that the reported mortality rate refers to cases confirmed in the laboratory by identification of the pathogen, and non-confirmed - e.g. asymptomatic - cases are not taken into account, so this data is only provisionally valid. According to the worldwide infection numbers published on a daily basis, the mortality rate is $3.4 \%$ [5]. It is approx. $0.86 \%$ in China, outside the Hubei province. A recently published study from China, which evaluated 1099 cases with confirmed SARS-CoV-2 infection up to 29th January 2020 , reports a mortality of $1.4 \%$ [7]. It is evident in various countries involved that these mortality numbers are subject to availability and number of tests performed in patient populations with mild as well as severe disease forms, to the preferred practice of registering only severe cases, and to the ability of a healthcare system to take controlled measures. Compare, for example, Iran (2.6\%), Italy (4.2\%) and South Korea (0.6\%). These available details will remain purely speculative in the absence of fundamental seroepidemiological studies yet to be conducted. They alone will record the actual prevalence of infection.

In order to deduce possible risks and complications of an infection in pregnancy and potential obstetric and neonatal outcome, experience from the SARS and MERS epidemics must also be taken into account at this point in time. In the following sections, therefore, the current state of knowledge regarding pneumonia in pregnancy and infections with other coronaviruses in pregnancy will be presented.

\section{Pneumonia in pregnancy}

Regardless of COVID-19, pneumonia is a known significant cause of morbidity and mortality of pregnant patients and represents the most important non-obstetric infection during pregnancy. In $25 \%$ of cases, it involves intensive care treatment and is an indication for mechanical ventilation [13]. Viral pneumonia is associated with higher morbidity and mortality in comparison with bacterial pneumonia [14]. The most important complications of pneumonia in pregnancy are premature rupture of the membranes (PROM), preterm labour, intrauterine fetal death (IUFD), intrauterine growth restriction (IUGR) and neonatal death $[13,15,16]$.

\section{SARS-CoV and pregnancy}

The SARS-CoV epidemic occurred between November 2002 and July 2003. During this period, 8422 patients suffered from pneumonia caused by the newly identified SARS-CoV. A total of 916 deaths have been reported in 29 countries [17]. No further
- Table 1 Typical symptoms of a SARS-CoV-2 infection [12].

\begin{tabular}{|l|c|}
\hline Symptom & Frequency \\
\hline Fever & $87.9 \%$ \\
\hline Dry cough & $67.7 \%$ \\
\hline Fatigue & $38.1 \%$ \\
\hline Sputum production & $33.4 \%$ \\
\hline Shortness of breath & $18.6 \%$ \\
\hline Sore throat & $13.9 \%$ \\
\hline Headache & $13.6 \%$ \\
\hline Myalgia/arthralgia & $14.8 \%$ \\
\hline Chills & $11.4 \%$ \\
\hline Nausea/vomiting & $5.0 \%$ \\
\hline Nasal congestion & $4.8 \%$ \\
\hline Diarrhoea & $3.7 \%$ \\
\hline Haemoptysis & $0.9 \%$ \\
\hline Conjunctival congestion & $0.8 \%$ \\
\hline
\end{tabular}

cases have been observed since 2004. Pneumonia was diagnosed in almost all known cases.

Given that pregnancy status was not recorded in the international survey of SARS-CoV infections during the epidemic, the exact number of cases of infected pregnant patients is not known, rendering impossible any systematic analysis of pregnancy outcomes. It is estimated that approx. 120 pregnant women were infected [18]. Small case series of pregnancy courses were published, and these will be presented as an overview in the following.

The largest published case series comprised 12 pregnant women from Hong Kong with confirmed SARS-CoV. Clinical and laboratory findings of these cases were identical to those of non-pregnant patients; pneumonia was diagnosed in all 12 cases by CT scan. Ventilation treatment was indicated in four female patients; three of them died over the further clinical course from respiratory failure or sepsis [19].

Seven women became ill during the first trimester. Four women suffered early abortion, two patients wanted termination of pregnancy for social indications, and one child was born at term and was healthy. Five patients contracted SARS after the 24th week of pregnancy (WOP). In three cases, an emergency C-section was performed for reduced general condition of the mother secondary to SARS-CoV infection (26th, 28th, 32nd WOP). The birth weight of all three children was appropriate for gestational age (AGA). On the other hand, those children who were born after recovery of the mother in the 33rd week of pregnancy and at term, presented IUGR associated with oligohydramnios.

Vertical transmission of SARS-CoV was not detected in any of the cases with live-birth children [20].

As regards outcome in the neonatal period, the authors report that surfactant administration for acute airways syndrome was indicated for the fetuses born in the 26th and 28th WOP. One child went on to develop bronchopulmonary dysplasia. Two children suffered gastrointestinal complications - necrotising enterocolitis in one case and ileum perforation in the other. Whether these pul- 
monary and gastrointestinal complications are to be regarded as being related to maternal SARS infection or as the result of premature birth, remains unclear because of the small amount of data available [21].

Of the 12 cases reported above, ten were compared in a casecontrol study with 40 non-pregnant, but SARS-CoV-infected women [22]. Cases and controls were matched for age, sex, profession, underlying illness, and risk area comprising a high number of cases of SARS-CoV-infected persons. This study demonstrated that pregnancy has a significant impact on the disease course and outcome of an infected patient: thus, hospital stay of pregnant patients was longer. The development of renal failure, sepsis or disseminated intravascular coagulopathy, as well as the need for intensive-care treatment, was occured significantly more often in the group of pregnant women. Mortality of pregnant infected patients was also significantly increased [22].

Another publication reports on the outcome of five pregnant patients suffering from a SARS-CoV infection in China [23]. In two cases, infection occurred in the second trimester, while three patients became ill during the last trimester of pregnancy. Whereas all the patients in this population also presented abnormal radiological findings, there was no fatality. In accordance with the above data, no vertical viral transmission onto the child was observed in this patient population either. Nor did the children in the published cases from the USA and Canada present any postpartum signs of infection [24-26].

\section{MERS-CoV and pregnancy}

The Middle East Respiratory Syndrome (MERS) is caused by a further, newly reported coronavirus: MERS-CoV. The zoonotic MERSCoV virus is excreted by infected camelids (dromedaries) and transferred to humans in a not yet fully understood way. The first cases of this viral disease were detected in April 2012 in Saudi Arabia, and with time it spread across the Arabian Peninsula, with focal outbreaks as far away as the USA and North Korea. So far, approx. 2500 cases have been confirmed, of which approx. 860 patients died. Human-to-human transmission is usually by droplet infection, with the incubation period being an average of 5.2 days. Similar to SARS, the male sex, advanced age and the presence of underlying conditions as well as the traditional handling of camelids have been identified as risk factors [27].

The clinical course of an infection is often asymptomatic in healthy patients or presents mild flu-like symptoms; infections of household contacts develop with moderate frequency [28]. Severe clinical courses may arise in immunocompromised patients and patients with underlying conditions such as chronic lung diseases, diabetes or chronic kidney disease [29] and are associated with the development of pneumonia and transition to acute respiratory distress syndrome. Diarrhoea often occurs as a concomitant symptom $[1,30]$.

So far, there is also only little data available on MERS-CoV infections in pregnancy. Nonetheless, the 11 reported symptomatic cases [31] demonstrated more severe courses than with an infection with SARS-CoV in pregnancy. It must remain uncertain whether this is the expression of the three-fold higher mortality rate of MERS in comparison with SARS or whether there are influencing factors specific to MERS.
Average maternal age was 33.7 years, and the gestational age at onset of infection was 26.3 weeks of pregnancy (WOP). The clinical course was comparable to the disease pattern of nonpregnant patients. Intensive-care treatment became necessary in six patients. Three patients died after delivery. As regards fetal outcome, three fatalities were reported - two fetuses suffered intrauterine death, one child died four hours after birth by $\mathrm{C}$-section in the 25th WOP. Two premature babies and five full-term children had unremarkable outcomes [31].

\section{Placental function and histology secondary to SARS-CoV infection and potential impact on the course of pregnancy}

Due to the small number of published case numbers of pregnant patients and their outcomes, the available literature on possible placental changes and the consequences for the course of pregnancy during an infection in graviditate is thin. While in this regard there is no published data on MERS, there is a study available involving seven female patients with SARS-CoV infection and an unremarkable case history [32]. These seven cases were treated in Hong Kong at the Princess Margaret Hospital. During the SARS epidemic, this hospital had the only obstetric department in Hong Kong which was allowed to treat pregnant SARS patients. The reported cases are part of the case series already mentioned above. Given the relevance and subsequent potential repercussions for the clinical management of patients with confirmed COVID-19 disease, the specific circumstances of these cases will once again be dealt with in more detail.

At the time of giving birth, three patients (Cases 1-3) were in the acute disease stage, with respiratory failure and the need for mechanical ventilation. Four patients (Cases 4-7) were considered cured at the time of delivery, with no indication for mechanical ventilation during the acute disease phase. Only the administration of oxygen was necessary in two cases for nine (Case 4) and 21 days (Case 5). Further complications of the individual cases are presented in $>$ Table 2.

In the three cases of an acute stage of illness, delivery by C-section was in the 26th, 28th and 32nd WOP. Two patients died over the further clinical course of respiratory failure (Cases 1 and 2).

In three cases (Cases $4,5,7$ ), delivery was in patients who had already recovered from their SARS disease. In two cases, delivery was after the 37th WOP (Cases 5, 7). One birth (Case 7) was induced and proceeded uneventfully with unremarkable Apgar scores and normal birth weight. One patient (Case 5) developed spontaneous contractions. Secondary C-section was performed for a pathological CTG with delivery of an SGA fetus with unremarkable Apgar scores.

Another patient (Case 4) went into premature labour with a subsequent uneventful spontaneous delivery in the 33rd WOP. The Apgar scores were also unremarkable.

In the two cases just presented, IUGR developed over the course of pregnancy. This became evident in each case with a decrease in fetal growth, with no Doppler ultrasound abnormalities of the umbilical artery. There was no Doppler ultrasound report of any other relevant vessels which would allow assessment of IUGR (middle cerebral artery, uterine arteries, ductus venosus). 


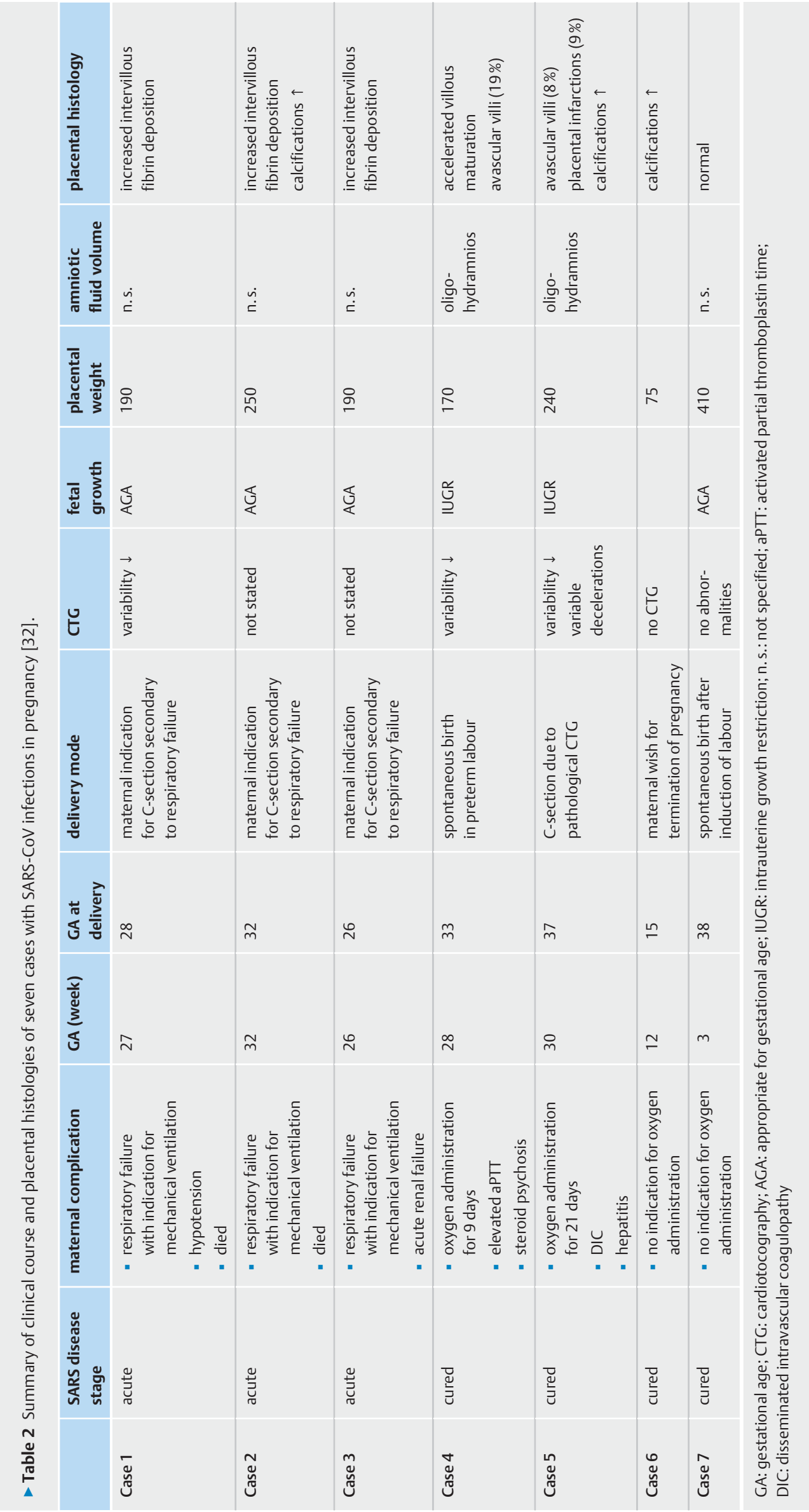


Histological examination of both placentas of the IUGR fetuses demonstrated a large number of avascular villi, as well an accelerated villous maturation (Case 4) or placental infarction and increased calcifications (Case 5).

The authors regard the large number of avascular villi as noteworthy in both cases. While there is no possible explanation in Case 4, a connection with disseminated intravascular coagulopathy is seen in Case 5 .

The authors also found no evidence for placental infection, in which manifestations of avascular villi typically develop. Therefore, vertical transmission of the SARS-CoV infection has so far not been histologically confirmed either.

The placentas of Cases 1-3 also showed signs of placental failure, here in the form of increased intervillous fibrin deposition. The authors consider these abnormalities to be the result of reduced placental perfusion secondary to hypoxia or shock [32].

Both patients whose onset of infection was in the first trimester did not present any placental abnormalities. In Case 6, in which termination of pregnancy was undertaken upon the mother's request due to the SARS infection, the histological examination of the placenta only showed increased calcifications with an otherwise normal placental structure, while a normal placental structure was reported for Case 7 with an infection during early pregnancy and delivery in the 38th WOP.

In summary and in view of the histological examinations, it may be assumed that infection after the first trimester can result in reduced placental function and theses pregnancies require intensive monitoring.

\section{The new SARS-CoV-2 and pregnancy}

At this point in time, there are two retrospective studies on pregnancies complicated by COVID-19 disease [33,34]. Over 19 cases were reported in all.

The first study ("Wuhan patient population") [34] comprises nine cases which presented between 20th January 2020 and 31st January 2020, inclusively, at the Zhongnan Hospital of Wuhan University. The second study ("Hubei patient population") [33] reports of nine patients infected with SARS-CoV-2 and ten neonates (eight singleton and one twin pregnancy), who were treated between 20th January 2020 and 5th February 2020 in five hospitals in Hubei.
In both studies, the clinical symptoms of an infection with SARS-CoV-2 were identical to those of cases involving non-pregnant female patients [4]. All cases had a high-risk exposure. Pneumonia developed in each case; typical infiltrates were detected by computed tomography in both study populations. Typical clinical symptoms of the "Wuhan patient population" are presented in - Table 3. In this patient population, the laboratory results showed decreased white blood cells and lymphocytes, mild thrombocytopaenia and elevated liver function tests.

None of the cases required mechanical ventilation. There were no fatalities either.

- Table 4 presents the maternal and obstetric outcome of the "Wuhan patient population", > Table $\mathbf{5}$ shows the neonatal outcome. For comparison, - Table 6 presents the obstetric and neonatal outcome of the "Hubei patient population". During COVID19 pneumonia, two cases of premature rupture of the membranes developed in the "Wuhan population", while three premature membrane ruptures were observed in the "Hubei population". Pathological CTGs were registered in the different patient populations in two and six cases, respectively. Whereas all patients included in the "Wuhan patient population" gave birth by C-section, there were two spontaneous births in the "Hubei patient population" and seven C-section deliveries.

\section{Transmission from mother to child}

At the present time, there is only little data available about the risk of vertical transmission from mother to child due to the small number of published cases. No case of such viral transmission was reported to have occurred during the SARS epidemic [20]. The risk of SARS-CoV-2 transmission was examined in the study recently published in the Lancet on the "Wuhan patient population". For this purpose, samples were taken from amniotic fluid, umbilical cord blood and throat swabs of the newborns immediately after delivery. All specimens were negative. Milk samples taken during this study immediately after the first postpartum breast engorgement were also unremarkable. In the study examining the "Hubei patient population", on the other hand, only throat swabs taken from the children were tested, not samples from the umbilical cord or amniotic fluid. In this patient population, all postpartum swabs were also negative. In a case study, placentas of three clinically symptomatic pregnant women with

- Table 3 Clinical characteristics and laboratory parameters of the "Wuhan patient population" [34].

\begin{tabular}{|c|c|c|c|c|c|c|c|c|c|c|}
\hline Clinical symptoms & Case 1 & Case 2 & Case 3 & Case 4 & Case 5 & Case 6 & Case 7 & Case 8 & Case 9 & n (\%) \\
\hline Fever on admission & no & yes & no & yes & yes & yes & yes & yes & yes & $7(78 \%)$ \\
\hline Postpartum fever & yes & yes & yes & yes & yes & no & no & no & yes & $6(67 \%)$ \\
\hline Myalgia & no & yes & no & no & yes & yes & no & no & no & $3(33 \%)$ \\
\hline Malaise & no & no & no & no & yes & yes & no & no & no & $2(22 \%)$ \\
\hline Cough & yes & yes & yes & no & no & yes & no & no & no & $4(44 \%)$ \\
\hline Breathlessness & no & no & no & yes & no & no & no & no & no & $1(11 \%)$ \\
\hline Sore throat & no & no & no & no & no & yes & yes & no & no & $2(22 \%)$ \\
\hline Diarrhoea & no & no & no & yes & no & no & no & no & no & $1(11 \%)$ \\
\hline
\end{tabular}




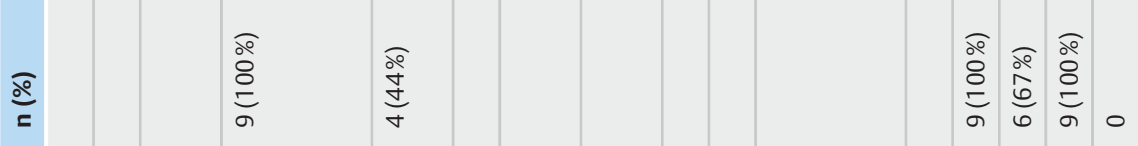

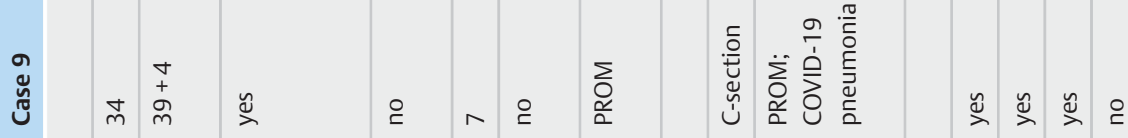

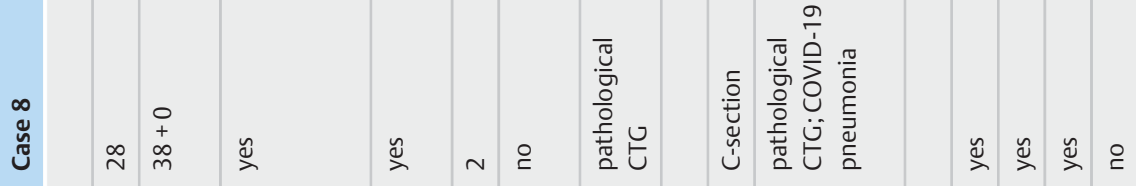

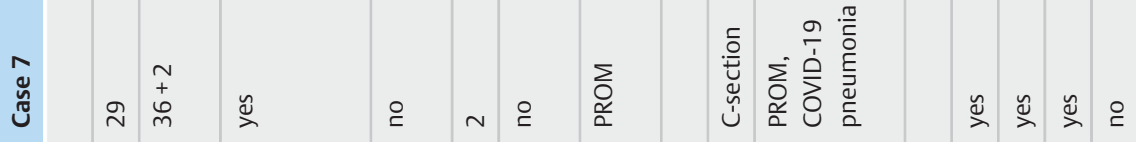

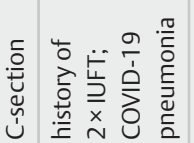

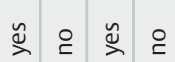
$\stackrel{a}{1}$

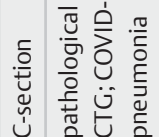

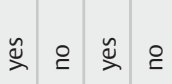

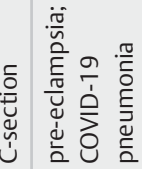

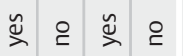

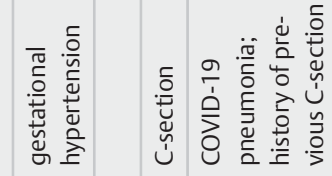

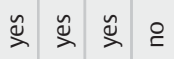

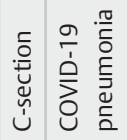

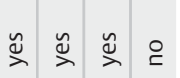

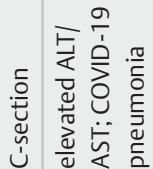

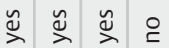

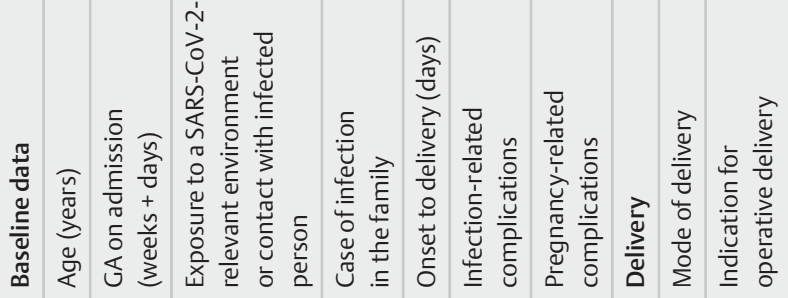

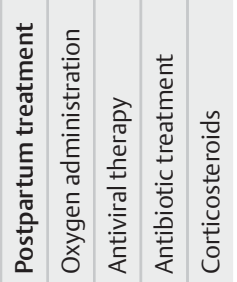


- Table 5 Neonatal outcome of the known SARS-CoV cases from Wuhan (“Wuhan patient population”) [34].

\begin{tabular}{|c|c|c|c|c|c|c|c|c|c|c|}
\hline & Case 1 & Case 2 & Case 3 & Case 4 & Case 5 & Case 6 & Case 7 & Case 8 & Case 9 & $n(\%)$ \\
\hline GA at delivery (weeks + days) & $37+2$ & $38+3$ & $36+0$ & $36+2$ & $38+1$ & $36+3$ & $36+2$ & $38+0$ & $39+4$ & \\
\hline Birth weight (g) & 2870 & 3730 & 3820 & 1880 & 2970 & 3040 & 2460 & 2800 & 3530 & \\
\hline Low birth weight $(<2500 \mathrm{~g})$ & no & no & no & yes & no & no & yes & no & no & $2(22 \%)$ \\
\hline Premature delivery & no & no & yes & yes & no & yes & yes & no & no & $4(44 \%)$ \\
\hline Apgar scores after $1 / 5 \mathrm{~min}$ & $8 / 9$ & $9 / 10$ & $9 / 10$ & $8 / 9$ & $9 / 10$ & $9 / 10$ & $9 / 10$ & $9 / 10$ & $8 / 10$ & \\
\hline Severe neonatal asphyxia & no & no & no & no & no & no & no & no & no & 0 \\
\hline Neonatal death & no & no & no & no & no & no & no & no & no & 0 \\
\hline IUFT & no & no & no & no & no & no & no & no & no & 0 \\
\hline
\end{tabular}

confirmed SARS-COV-2 infection were examined. No infection was diagnosed in any of the newborns. No histopathological correlates for infection were found in the placentas [35].

In summary, at the present time and based on very low case numbers of published pregnancies and their outcomes as well as on experience gained during the SARS epidemic, it does not appear that there is any intrauterine transmission of SARS-COV-2 onto the fetus.

Nevertheless, caution is needed: neonatologists should closely monitor children of infected mothers to be able to detect an infection early. As it is not conclusively clear whether infections can develop in utero or in the peripartum phase, children of infected mothers should be isolated after birth for the protection of other newborns.

\section{Neonatal outcome}

The following is known about neonatal outcome from both studies: all the children in both patient populations had unremarkable Apgar scores after one and five minutes. Elevated cardiac enzymes were discovered in one child of the "Wuhan patient population" on the first postpartum day, but these were of no clinical relevance. No neonatal fatalities were reported. In contrast, in the "Hubei patient population", one child died after birth in the $34+5$ WOP of multiple organ failure with disseminated intravascular coagulopathy on its ninth day of life. On the whole, outcome was worse for the "Hubei patient population" than for the "Wuhan patient population". Thus, respiratory distress syndrome developed in six newborns, followed by gastrointestinal symptoms $(n=4)$, fever $(n=2)$, tachycardia $(n=1)$ and vomiting $(n=1)$. According to the authors, COVID-19 disease was not diagnosed in any of the children. In the "Wuhan patient population", on the other hand, one child tested positive for SARS-CoV-2 36 hours post partum. The assumption at the moment is that the child became infected post partum. All the other reported children had an unremarkable neonatal period ( $\bullet$ Table 5 ).

\section{Management of infected pregnant patients}

With regard to management of infected pregnant women, the authors of two recently published reviews $[36,37]$ regard it as appropriate at the moment to observe the following measures:
- Treatment regarded as appropriate for non-pregnant cases of infection should not be withheld from pregnant patients merely because of their state of pregnancy, provided there are no clear contraindications for the available therapy.

- Various therapeutic options are currently under consideration (e.g. remdesivir, hydroxychloroquine). Studies on several treatment options have already been started. Further developments need to be awaited. Ultimately, benefit and potential risks for mother and child should be carefully weighed up, as with any form of treatment in pregnancy.

- With suspected cases, the decision to isolate pregnant women should be made generously and early.

- Tests should be carried out for SARS-CoV-2 and possible (bacterial and viral) co-infections. If necessary, oxygen support should be given, and mechanical ventilation should be commenced early should signs of respiratory failure develop.

- Empiric antibiotic treatment for secondary bacterial infections is indicated. Furthermore, blood cultures are recommended before starting any antibiotic therapy in order to adjust treatment if necessary as the clinical course develops.

- As regards fetal monitoring, regular CTG examinations and regular follow-up checks for growth, as well as Doppler and amniotic fluid examinations should be performed to exclude placental failure with the development of IUGR.

- As regards the mode of delivery for infected pregnant women, no recommendation can be given at the present moment because of the small number of cases. It is currently considered improbable that infection of the child can occur in the birth canal.

\section{Breastfeeding in cases of suspected infection or confirmed SARS-CoV-2 infection}

Given that no pathogen has been isolated in maternal milk in the studies carried out to date, transmission via breastfeeding is currently regarded as improbable. In case of suspected infection or after confirmed infection of the mother, the milk should be pumped off and feeding should be provided by a healthy assistant. For this situation, the European Institute for Breastfeeding and Lactation recommends sterilisation of all used vessels and pump sets in addition to adequate hand hygiene [38]. These rec- 


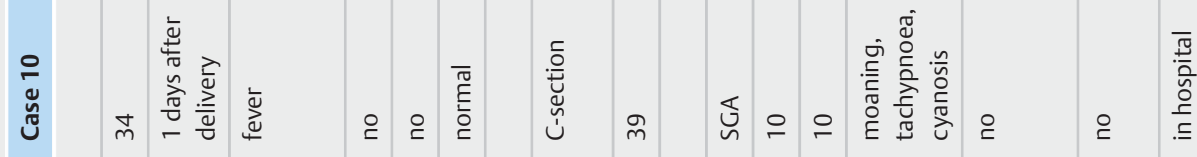

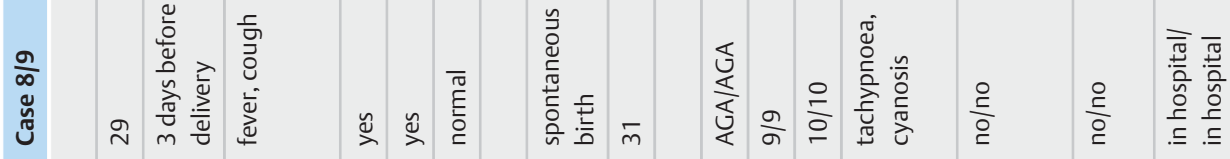

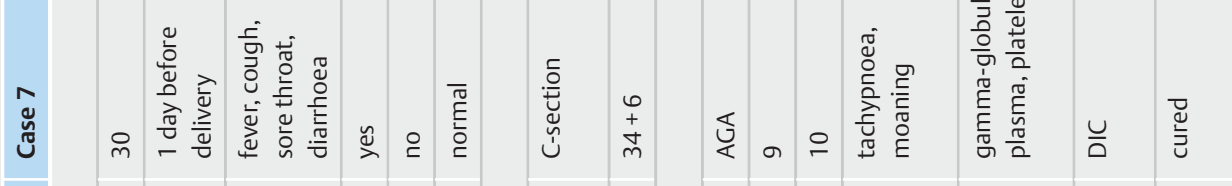

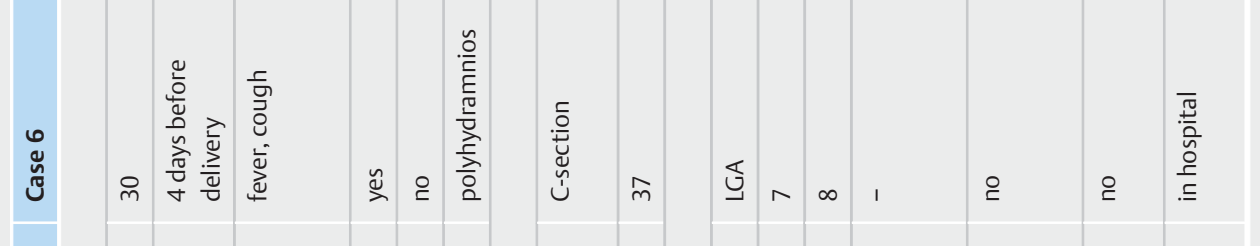

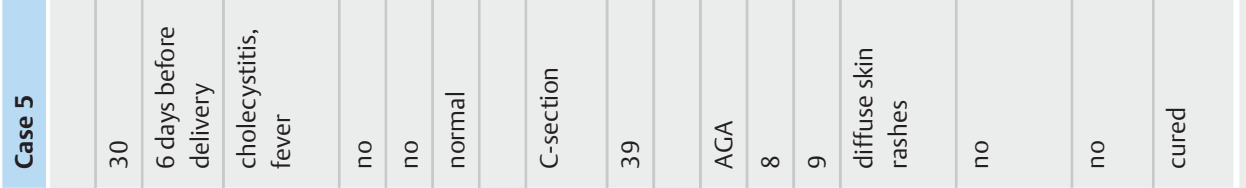

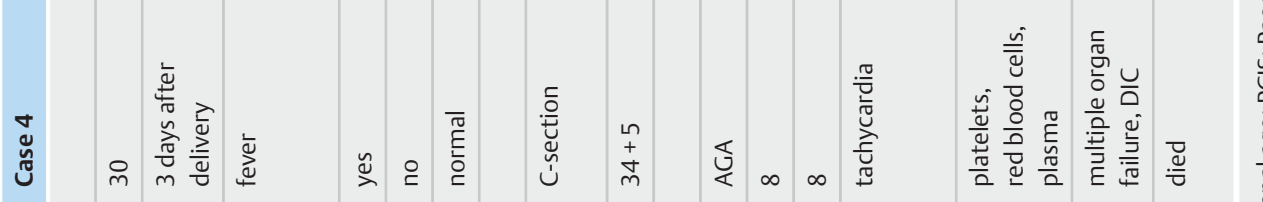

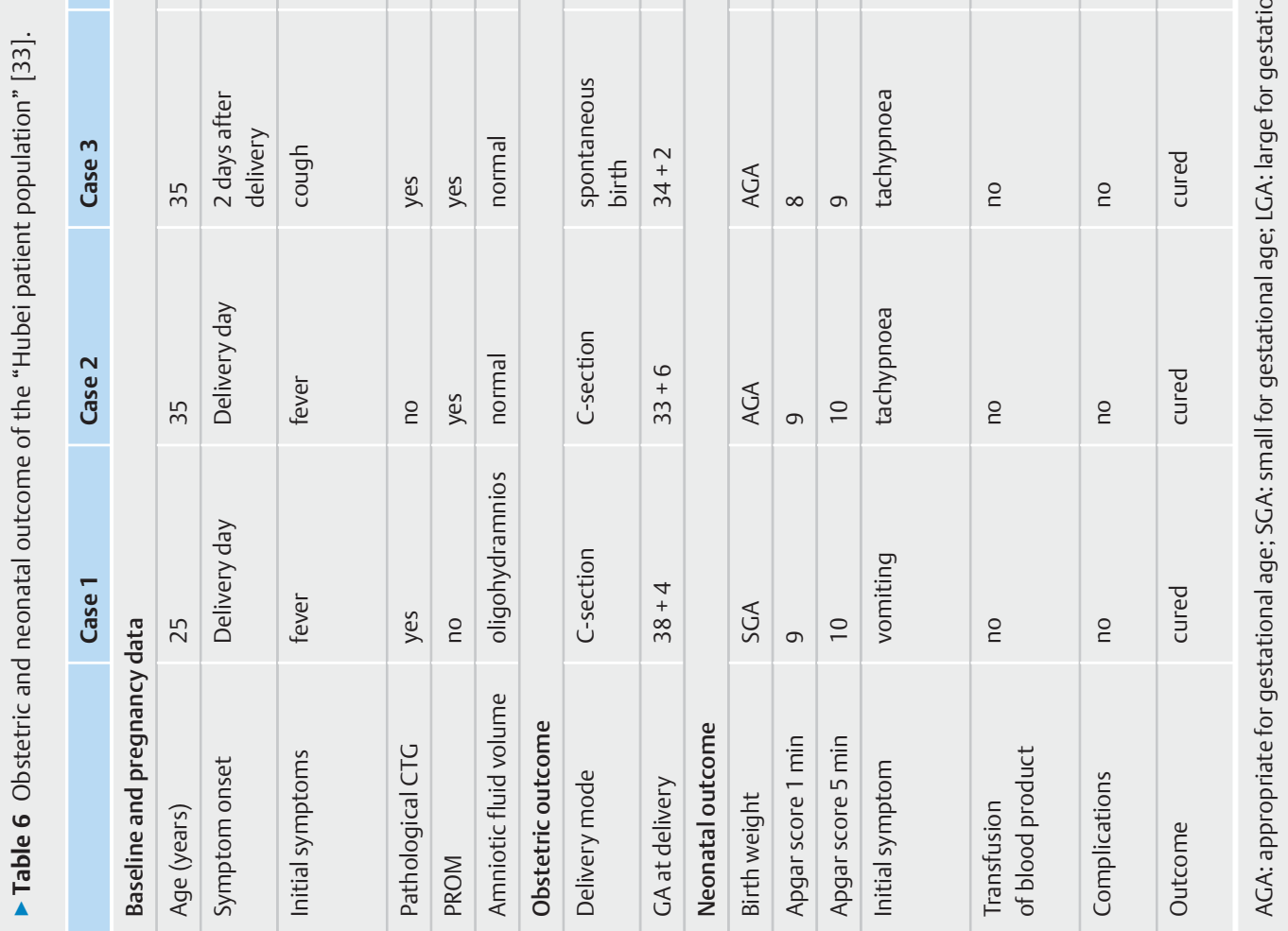


ommendations may be subject to change if new findings are published. Furthermore, by March 3rd, 2020, the German Board and College of Obstetrics and Gynecology (GBCOG), in collaboration with Professional Association of Gynecologists (BVF) and German Society for Gynecology and Obstetrics e. V. (DGGG) published a "FAQ for pregnant women and their families" [39].

\section{Conclusion}

In summary, it can be confirmed that the literature available on the management of pregnant women infected with SARS-CoV-2 is very limited. Pregnant women with confirmed infection and their fetuses should be closely supervised and monitored to be able to recognise early any clinical deterioration of mother and child. At the moment, it is to be assumed that pregnancy can complicate the clinical course of COVID-19 disease and may be associated with a higher mortality rate, but by far not as bad as with MERS or SARS. Pregnant women are at particular risk of respiratory virus infections, especially influenza. On the other hand, given their age, they usually belong to a patient population with a lower risk of developing severe COVID-19 clinical courses. At the moment there is no indication of intrauterine virus transmission to the fetus, nor for virus transmission via breastfeeding after a cured infection.

\section{Conflict of Interest}

The authors declare that they have no conflict of interest.

\section{References}

[1] Hui DS. Epidemic and Emerging Coronaviruses (Severe Acute Respiratory Syndrome and Middle East Respiratory Syndrome). Clin Chest Med 2017; 38: 71-86

[2] Report It. Coronaviridae. 2011. Online: https://talk.ictvonline.org/ictvreports/ictv_9th_report/positive-sense-rna-viruses-2011/w/posrna_ viruses/222/coronaviridae; last access: 04.03.2020

[3] Li Q, Guan X, Wu P et al. Early Transmission Dynamics in Wuhan, China, of Novel Coronavirus-Infected Pneumonia. N Engl 」 Med 2020. doi:10.1056/NEJMoa2001316

[4] Huang C, Wang Y, Li X et al. Clinical features of patients infected with 2019 novel coronavirus in Wuhan, China. Lancet 2020; 395: 497-506

[5] Dong E, Du H, Gardner L. An interactive web-based dashboard to track COVID-19 in real time. Lancet Infect Dis 2020. doi:10.1016/S1473-3099 (20)30120-1

[6] Zhu N, Zhang D, Wang W et al. A Novel Coronavirus from Patients with Pneumonia in China, 2019. N Engl J Med 2020; 382: 727-733

[7] Guan W-J, Ni Z-Y, Hu Y et al. Clinical Characteristics of Coronavirus Disease 2019 in China. N Engl J Med 2020. doi:10.1056/NEJMoa2002032

[8] Wu Z, McGoogan JM. Characteristics of and Important Lessons From the Coronavirus Disease 2019 (COVID-19) Outbreak in China: Summary of a Report of 72314 Cases From the Chinese Center for Disease Control and Prevention. JAMA 2020. doi:10.1001/jama.2020.2648

[9] Holshue ML, DeBolt C, Lindquist S et al. First Case of 2019 Novel Coronavirus in the United States. N Engl J Med 2020; 382: 929-936

[10] Yu ITS, Li Y, Wong TW et al. Evidence of Airborne Transmission of the Severe Acute Respiratory Syndrome Virus. N Engl J Med 2004; 350: 1731 1739
[11] Yong Z, Cao C, Shuangli Z et al. Notes from the Field: Isolation of 2019nCoV from a Stool Specimen of a Laboratory-Confirmed Case of the Coronavirus Disease 2019 (COVID-19). China CDC Weekly 2020. Online: https://flutrackers.com/forum/forum/-2019-ncov-new-coronavirus/2019-ncov-studies-research-academia/830233-china-isolation-of2019-ncov-from-a-stool-specimen-of-a-laboratory-confirmed-case-ofthe-coronavirus-disease-2019-covid-19; last access: 05.03.2020

[12] WHO. Report of the WHO-China Joint Mission on Coronavirus Disease 2019 (COVID-19). 2020. Online: https://www.who.int/docs/defaultsource/coronaviruse/who-china-joint-mission-on-covid-19-final-report. pdf; last access: 04.03.2020

[13] Madinger NE, Greenspoon JS, Gray Ellrodt A. Pneumonia during pregnancy: Has modern technology improved maternal and fetal outcome? Am J Obstet Gynecol 1989; 161: 657-662

[14] Rigby FB, Pastorek JG. Pneumonia During Pregnancy. Clin Obstet Gynecol 1996; 39: 107-119

[15] Benedetti T], Valle R, Ledger WJ. Antepartum pneumonia in pregnancy. Am J Obstet Gynecol 1982; 144: 413-417

[16] Berkowitz K, LaSala A. Risk factors associated with the increasing prevalence of pneumonia during pregnancy. Am J Obstet Gynecol 1990; 163: 981-985

[17] WHO. Consensus Document on the Epidemiology of Severe Acute Respiratory Syndrome (SARS). 2003. Online: https://www.who.int/csr/sars/ en/WHOconsensus.pdf; last access: 04.03.2020

[18] Anker M. Pregnancy and emerging diseases. Emerg Infect Dis 2007; 13: 518-519; author reply 519

[19] Wong SF, Chow KM, Leung TN et al. Pregnancy and perinatal outcomes of women with severe acute respiratory syndrome. Am J Obstet Gynecol 2004; 191: 292-297

[20] Ng PC, Leung CW, Chiu WK et al. SARS in newborns and children. Biol Neonate 2004; 85: 293-298

[21] Shek CC, Ng PC, Fung GP et al. Infants born to mothers with severe acute respiratory syndrome. Pediatrics 2003; 112: e254

[22] Lam CM, Wong SF, Leung TN et al. A case-controlled study comparing clinical course and outcomes of pregnant and non-pregnant women with severe acute respiratory syndrome. BJOG 2004; 111: 771-774

[23] Zhang JP, Wang YH, Chen LN et al. [Clinical analysis of pregnancy in second and third trimesters complicated severe acute respiratory syndrome]. Zhonghua Fu Chan Ke Za Zhi 2003; 38: 516-520

[24] Robertson CA, Lowther SA, Birch T et al. SARS and Pregnancy: A Case Report. Emerg Infect Dis 2004; 10: 345-348

[25] Stockman LJ, Lowther SA, Coy K et al. SARS during Pregnancy, United States. Emerg Infect Dis 2004; 10: 1689-1690

[26] Yudin MH, Steele DM, Sgro MD et al. Severe acute respiratory syndrome in pregnancy. Obstet Gynecol 2005; 105: 124-127

[27] WHO. Middle East respiratory syndrome coronavirus (MERS-CoV). 2019 Online: https://www.who.int/emergencies/mers-cov/en/; last access: 04.03.2020

[28] Drosten C, Meyer B, Muller MA et al. Transmission of MERS-coronavirus in household contacts. N Engl J Med 2014; 371: 828-835

[29] Yadav S, Rawal G, Baxi M. An Overview of the Latest Infectious Diseases around the World. 2016. J Community Health Manag 2016; 3: 41-43. doi:10.5958/2394-2770.2016.00014.4

[30] Robert Koch-Institut. Informationen des RKI zU MERS-Coronavirus. 2019. Online: https://www.rki.de/DE/Content/InfAZ/M/MERS_ Coronavirus/MERS-CoV.html; last access: 05.03.2020

[31] Alfaraj SH, Al-Tawfiq JA, Memish ZA. Middle East Respiratory Syndrome Coronavirus (MERS-CoV) infection during pregnancy: Report of two cases \& review of the literature. J Microbiol Immunol Infect 2019; 52: 501-503 
[32] Ng WF, Wong SF, Lam A et al. The placentas of patients with severe acute respiratory syndrome: a pathophysiological evaluation. Pathology 2006; 38: $210-218$

[33] Zhu H, Wang L, Fang $C$ et al. Clinical analysis of 10 neonates born to mothers with 2019-nCoV pneumonia. Transl Pediatr 2020; 9: 51-60

[34] Chen H, Guo J, Wang C et al. Clinical characteristics and intrauterine vertical transmission potential of COVID-19 infection in nine pregnant women: a retrospective review of medical records. Lancet 2020. doi:10.1016/S0140-6736(20)30360-3

[35] Chen S, Huang B, Luo DJ et al. [Pregnant women with new coronavirus infection: a clinical characteristics and placental pathological analysis of three cases]. Zhonghua Bing Li Xue Za Zhi 2020; 49: E005

[36] Liang H, Acharya G. Novel corona virus disease (COVID-19) in pregnancy: What clinical recommendations to follow? Acta Obstet Gynecol Scand 2020. doi:10.1111/aogs. 13836
[37] Rasmussen SA, Smulian JC, Lednicky JA et al. Coronavirus Disease 2019 (COVID-19) and Pregnancy: What obstetricians need to know. Am J Obstet Gynecol 2020. doi:10.1016/j.ajog.2020.02.017

[38] Europäisches Institut für Stillen und Laktation e.V. Coronavirus/ COVID-19 und Stillen: Aktuelle Empfehlungen. 2020. Online: http:// www.stillen-institut.com/de/coronavirus-covid-19-und-stillen-aktuelleempfehlungen.html?fbclid=IwAR3F8_iFQDAmyHxhGHtGIXPLy8 VPGKFW9DIOsFKH2cTqE2ci6_rEN7yed3c; last access: 09.03.2020

[39] Hinweise und FAQ vom Berufsverband der Frauenärzte e.V. (BVF) und der Deutschen Gesellschaft für Gynäkologie und Geburtshilfe e.V. (DGGG) vereint im German Board and College of Obstetrics and Gynecology (GBCOG) zu den Risiken des Coronavirus (SARS-CoV-2) für schwangere Frauen und Säuglinge. Online: https://www.dggg.de/news/ hinweise-und-faq-zum-coronavirus-fuer-schwangere-und-saeuglinge$1181 /$; last access: 19.03 .2020 